\title{
How and How Not to Take on Brueckner's Sceptic
}

\author{
Christoph Kelp \\ Institute of Philosophy, KU Leuven \\ christoph.kelp@,hiw.kuleuven.be
}

Brueckner's book brings together a carrier's worth of papers on scepticism. Brueckner is what is perhaps best described as a critical sympathiser of the sceptic and surely, as far as his sympathies reach, one of his most powerful allies. One of the book's core characteristics - especially of the (temporally) earlier papers therein - is Brueckner's relentless efforts to point out the flaws in extant attacks on the sceptic, to then take the core ideas of these attacks and turn them into precise and powerful arguments against the sceptic, only to show that, at the end of the day, the sceptic survives them unscathed. At the same time, the book reveals an unmistakable development in Brueckner's thinking over the years, a development away from the initially quite staunch defences of the sceptic to much more nuanced views that show an acute awareness of the limitations and in some cases even the failure of sceptical arguments. Thanks to its richness and to Brueckner's careful argumentation, the book will be of interest for anyone with even a vague interest in scepticism. It is absolutely unmissable for those venturing to do serious work on the issue: anyone who wishes to take scepticism seriously must take on Brueckner's sceptics.

The book is subdivided into four parts each of which is devoted to a distinct type of sceptical problem beginning in Part I with transcendental arguments against scepticism, which venture to establish our knowledge of an external world from uncontroversial facts about our minds such as that we are subjects of experiences of a 
certain kind or that we speak a meaningful language. Part II addresses anti-sceptical arguments from content externalism, the thesis that the contents of our words, sentences and various intentional states are determined partly by external, causal facts about the environing world. The central thought here is that if content is fixed externally in this way, we can come to know at least that there is an external world and thus can get some anti-sceptical mileage out of content externalism. Sceptical worries about self-knowledge, arising from an alleged incompatibility of privileged knowledge of one's own mind with externalism about the content of intentional states, are the focus of Part III. Finally, in Part IV the discussion turns to so-called closure-based arguments for scepticism, which threaten to establish the radical sceptical conclusion that we know next to nothing about the external world on the basis of a plausible principle that licences extensions of knowledge across known entailments and the plausible claim that we do not know that we are not globally deceived.

While it would be impossible to review all the different parts of the book in any detail, I would like to take a closer look at a couple of Brueckner's more anti-sceptical arguments from Parts II and IV, which he also describes as reflecting his current thinking on the issues. In true Brueckner-style, I will try to defend the sceptic, this time against Brueckner, and then offer a different kind of solution that circumvents the problems Brueckner's own proposals face.

Brueckner thinks that, given the plausible assumption of content externalism, the following argument has anti-sceptical import:

(A) If I am a BIV [i.e. a brain in a vat], then I am not thinking that a palm tree is near.

(B) I am thinking that a palm tree is near. 
(G) I am not a BIV. (p.168)

Brueckner points out that content externalism gives us (A) and that (B) can be known for instance by answering the following self-knowledge quiz:

Q: What are you thinking?

A: (a) That quantum entanglement is amusing.

(b) That cows are purple.

(c) That North America is south of South America.

(d) That a palm tree is near. (Ibid.)

I agree with Brueckner that statements like (B) can often be known and that they may even be known in ways similar to the self-knowledge quiz. However, I remain unconvinced that the self-knowledge quiz will be useful for Brueckner in an anti-sceptical argument from content externalism for at least two reasons.

To bring out the first of these reasons, I need to begin with a brief digression. Notice that there are at least two ways in which I may know where I am at the moment: (i) I may know that I am here now (call the embedded proposition HERE). (ii) I may also know that I am currently sitting in my office (call the embedded proposition OFFICE). Notice that I can know HERE no matter whether I am on Earth or a BIV on Alpha Centauri. Knowledge of $H E R E$ does not allow me to calibrate my position in space. As opposed to that, knowledge of OFFICE does allow me to calibrate my position in space. Now consider a sceptic about location, a sceptic who thinks that we lack knowledge of location. Of course, I can argue against such a sceptic that I know HERE. But I don't think the sceptic should be worried by my argument. On the contrary, he may point out that he never meant to deny that I could know HERE. He wasn't that radical of a sceptic. What he meant to deny was that I have knowledge of location that is of any substance, 
knowledge that allows me to calibrate my position in space, such as knowledge of OFFICE.

Now, my suggestion is to view Brueckner's sceptic as a sceptic about location in modal space. Such a sceptic may concede that I can have knowledge of location in modal space analogous to knowledge of $H E R E$, which I can have whether or not I am in a normal world or a vat world. He will only deny that I can have substantive knowledge of location in modal space, knowledge that would allow me to calibrate my position in modal space. Brueckner's argument is ineffective against this kind of sceptic because it does not licence such knowledge. To see this we need only notice that even if the expression 'BIV' is true of me when interpreted as an expression of English, I can still run the argument from $(\mathrm{A})$ to $(\mathrm{C})$ and on its basis can come to know that I am not a BIV. Of course, in this case, the content of my use of 'BIV' differs from the content of the expression as interpreted in English. But that no more prevents me from knowing that I am not a BIV, than the fact that the expression 'chat' has a different content when interpreted in English prevents a speaker of French from knowing that the cat is on the mat. The argument from $(\mathrm{A})$ to $(\mathrm{C})$ can give me knowledge that I am not a BIV whether or not I am in a normal world or a vat world. As a result, it does not allow me to calibrate my position in modal space, does not give me substantive knowledge of location in modal space and hence does not allow Brueckner to make progress against the kind of sceptic under consideration.

The second reason why Brueckner's argument does not convince me has to do with my alleged knowledge of $(\mathbf{B})$. Brueckner's thought seems to be that the fact that I can answer the self-knowledge quiz positions me to know (B). Although I agree that I can answer this self-knowledge quiz, it is far from clear that I can answer a self-knowledge 
quiz with a slightly different set of options including (e) it merely seems to me that I have a thought with a determinate content, while, in fact I don't. (Given content externalism, this option might be true at a world at which I am continuously moved across environments with very different natures and never stay long enough in one environment for it to fix the contents of my thoughts or at a world at which I have been brought into existence a splitsecond ago with a rich set of ostensible memories of the past.) The sceptic might argue that in order to know (B), I must be able to answer not only Brueckner's version of the self-knowledge quiz but also a version that includes (e). Since I patently cannot answer any such self-knowledge quiz, I do not know (B), contrary to what Brueckner claimed.

At this point there are a couple of responses one might give on behalf of Brueckner. First, one could argue that the type of sceptical scenario under consideration is one in which I have been envatted in a non-changing environment for a sufficiently long time and that therefore I am entitled to assume that I am not a BIV of the kind of which (e) would be true. However, this move effectively makes the anti-sceptical import of Brueckner's argument contingent on the prior success of a different anti-sceptical argument. As a result, my hopes that Brueckner's argument would allow me to make unconditional progress against the sceptic, progress that does not rely on prior antisceptical achievements, are frustrated. What's more, Brueckner will also face a trivialisation worry for the content externalist argument. After all, it might turn out that the anti-sceptical argument that works against the sceptic who worries that I might be in (e) will also work against the sceptic Brueckner takes on in his paper. In that case content externalism is simply superfluous in the argument against the sceptic.

Second, one could maintain on behalf of Brueckner that alternatives like (e) are simply not relevant so that I can know that I think a palm tree is near even though I cannot 
rule out possibility (e). This move trivialises the anti-sceptical import of the argument from (A) to (C). After all, as Brueckner himself is well aware (p. 168), we need a closure principle for knowledge in order to come to know the conclusion of the argument. However, given the relevant alternatives theory of knowledge under consideration here, the closure principle will generate the anti-sceptical result Moore-style without appeal to content externalism. For these reasons I am much less optimistic about a successful substantive anti-sceptical argument from content externalism than Brueckner appears to be.

I would now like to move on to Brueckner's take on closure-based scepticism. Brueckner states the argument in the standard way:

(1) If I know that $\mathrm{h}(=\mathrm{I}$ have hands), then $\mathrm{I}$ know that $\sim \mathrm{SK}(=\mathrm{I}$ am not a brain in a vat).

(2) I do not know that $\sim \mathrm{SK}$.

(3) I do not know that h. (p. 354)

(1) is motivated by the plausible closure principle for knowledge. (2) is motivated by the following underdetermination principle:

(UP) If $\mathrm{S}$ has justification for believing that $\varphi$, and $\psi$ is incompatible $\varphi$, then S's evidence for $\varphi$ favours $\varphi$ over $\psi$. (p. 368)

in conjunction with the claim that

$(\sim$ F) My experiential evidence for $\sim$ SK does not favour $\sim$ SK over SK. (Ibid.)

and the thesis that knowledge requires justification. Brueckner sympathises with this type of sceptical argument but finds a fly in the ointment. He takes $(\sim \mathrm{F})$ to be motivated by the fact that it is possible for me to have the experiential evidence I have, while SK obtains (p. 379). That is to say, however, that the motivation for $(\sim \mathrm{F})$ appears to be that my 
experiential evidence does not entail $\sim \mathrm{SK}$. But, the thought is, it is hard to see why the failure of entailment should motivate $(\sim \mathrm{F})$ except if one also assumes an infallibilist conception of justification according to which my evidence favours $\varphi$ over $\psi$ in the way required by (UP) only if it entails $\varphi$. However, such a conception of evidence is not only implausibly strong but would also suffice to establish the sceptical result without appeal to $(\mathrm{UP})$ and $(\sim \mathrm{F})$. The apparently plausible sceptical argument from $(\mathrm{UP})$ and $(\sim \mathrm{F})$ threatens to collapse into an argument from a patently implausible infallibilist conception of justification. (p. 380)

I think that Brueckner's sceptic is actually not in as bad a predicament as Brueckner fears he might be. For starters, there is reason to think that Brueckner misdiagnoses the motivation for $(\sim \mathrm{F})$. To see this, consider a case in which I am looking at my friend's new canary, Tweety. Suppose I don't know that Tweety is a canary because my evidence does not favour Tweety's being a canary over Tweety's being a yellowhammer. Given Brueckner's proposed diagnosis of the motivation of $(\sim \mathrm{F})$, we would expect that the explanation of the fact that my evidence does not favour one alternative over the other to be that it is possible that I have the evidence I have while Tweety is a yellowhammer. However, this explanation cannot plausibly be correct. After all, arguably, if Tweety is a canary, then Tweety is necessarily a canary. So, since Tweety in fact is a canary, it is not possible that he is a yellowhammer and so it's not possible that I have the evidence I have while Tweety is a yellowhammer. This should also make us suspicious whether Brueckner's possibility claim really does motivate $(\sim \mathrm{F})$.

A more plausible account of favouring is probabilistic. According to this account one's evidence, e, does not favour $\varphi$ over $\psi$ just in case $\operatorname{Pr}(\varphi \mid \mathrm{e})=\operatorname{Pr}(\psi \mid \mathrm{e})$. This account can accommodate the Tweety case. After all, even if Tweety couldn't be a 
yellowhammer, it is plausible (and certainly possible) that, as far as I am concerned at least, $\operatorname{Pr}($ Tweety is yellowhammer $\mid \mathrm{e})=\operatorname{Pr}($ Tweety is a canary $\mid \mathrm{e})$. The probabilistic account of favouring can also help the sceptic to a comeback. After all, it is no less plausible, in the sceptical case, that $\operatorname{Pr}(\sim \mathrm{SK} \mid \mathrm{e})=\operatorname{Pr}(\mathrm{SK} \mid \mathrm{e})$ than it is plausible, in the Tweety case, that $\operatorname{Pr}($ Tweety is yellowhammer $\mid \mathrm{e})=\operatorname{Pr}($ Tweety is a canary $\mid \mathrm{e})$. At the same time, it goes without saying that the probabilistic account of favouring does not involve a commitment to an infallibilist conception of justification. So, the sceptical argument from $(\mathrm{UP})$ and $(\sim \mathrm{F})$ can go through without collapsing into an argument from implausible infallibilist premises.

So are we in the end forced to accept Brueckner's sceptic's conclusion? The answer, I think, is 'no' (fortunately). I cannot, of course, hope to give a detailed solution to the problem of scepticism here. So, I will here only sketch the strategy I think is most promising as well as a (fairly suggestive) reason why I think it is promising. The root of the sceptical problem, I think, is that it places such a heavy epistemic burden on the agent. It is the agent's evidence that must do all the epistemic work. In fact, the burden is so heavy that no epistemic agent who is anything like us can hope to lift it simply by deploying his own powers. However, a burden too heavy for a single agent might be lifted with external help. The external help, I think, will have to come from the agent's environment. If we require that the environment be sufficiently knowledge-friendly, we can relieve the agent of some of the weight of his burden, which might then become liftable after all. In other words, I think that what we need against the sceptic is a moderate externalist account of knowledge according to which one has knowledge just in case sufficiently strong (but fallible) cognitive powers are deployed in a sufficiently knowledge-friendly environment. The thought here is that the stronger one's powers, the less of a contribution one needs 
from the environment, and the more the environment contributes, the less one needs in the way of strength in power.

At what point does moderate externalism block the sceptical argument? That depends on how view is implemented in detail. One could deny that knowledge requires justification, one could deny (UP) - for instance, by denying that one's evidence needs to raise the probability of a hypothesis vis-à-vis all alternatives — or one could deny $(\sim \mathrm{F})$ - for instance, by placing an externalist constraint on evidence and holding that in suitable environments one's evidence does favour $\sim$ SK over SK.

Doesn't adopting a moderate externalist account of knowledge simply beg the question against the sceptic? That depends on how one motivates externalism. If one motivated it simply by the fact that it solves the problem of scepticism, one would beg the question. (Brueckner himself presses this charge against a certain kind of externalist response to scepticism. (p. 378)) However, it is not clear that one needs to motivate externalism in this way. The most promising alternative proceeds by looking at how externalism fares in explaining various relevant data (various intuitions, attribution behaviour, epistemological problems, plausible epistemic principles) in comparison with sceptical accounts of knowledge. My prediction is that such a comparison will cast a favourable light on externalism. 